\title{
Self-reported Gastrointestinal Side Effects of Antifibrotic Drugs in Dutch Idiopathic Pulmonary Fibrosis patients
}

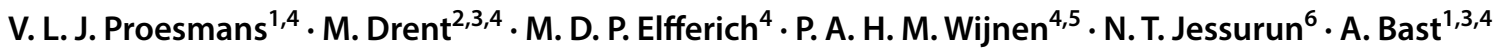

Received: 27 May 2019 / Accepted: 5 August 2019 / Published online: 22 August 2019

(c) The Author(s) 2019

\begin{abstract}
Purpose Idiopathic pulmonary fibrosis (IPF) is an inexorably progressive disease, which has a great impact on patients' lives. Pirfenidone and nintedanib are approved and recommended antifibrotic drugs for patients with IPF. The aim of this study was to evaluate self-reported gastrointestinal side effects of antifibrotic drugs in 176 Dutch IPF patients.

Methods A cross-sectional web-based anonymous survey about complaints and side effects was conducted among IPF patients in the Netherlands. Logistic regression was used to quantify whether pirfenidone and nintedanib caused complaints of nausea, vomiting, diarrhoea, appetite loss, weight loss or loss of taste or smell perception.

Results The questionnaire was completed by 176 IPF patients, 71 of whom used pirfenidone and 85 nintedanib, while 20 patients did not use any antifibrotic drugs. Nintedanib users reported complaints of diarrhoea, vomiting, weight loss and loss of appetite $(p<0.01)$. Nausea was a significant adverse reaction $(p<0.05)$. Pirfenidone caused increased appetite loss $(p<0.01)$ and the risk of weight loss $(p<0.05)$. The increase in loss of appetite and weight loss did not differ significantly between the two drugs.

Conclusion The current study showed that nintedanib causes a significant increase in diarrhoea, vomiting, weight loss and loss of appetite, while pirfenidone led to loss of appetite. Our results suggest new avenues regarding dietary recommendations for IPF patients.
\end{abstract}

Keywords Antifibrotic drugs $\cdot$ Idiopathic pulmonary fibrosis $\cdot$ IPF $\cdot$ Nintedanib $\cdot$ Pirfenidone $\cdot$ Side effects $\cdot$ Treatment

\section{Introduction}

Idiopathic pulmonary fibrosis (IPF) is a serious, inexorably progressive disease, which usually affects middle-aged and older adults. While IPF is by definition "idiopathic" (i.e. of

M. Drent

m.drent@antoniusziekenhuis.nl

1 Venlo Campus, Maastricht University, Venlo, The Netherlands

2 ILD Center of Excellence, Department of Pulmonology, St. Antonius Hospital, Koekoekslaan 1, 3435 CM Nieuwegein, The Netherlands

3 Department of Pharmacology and Toxicology, FHML, Maastricht University, Maastricht, The Netherlands

4 ILD Care Foundation Research Team, Ede, The Netherlands

5 Central Diagnostic Laboratory, Maastricht University Medical Centre, Maastricht, The Netherlands

6 Netherlands' Pharmacovigilance Centre Lareb, 's Hertogenbosch, The Netherlands unknown cause), the list of potential fibrogenic triggers that have been associated with IPF includes smoking, chronic microaspiration of gastric content and chronic infection. IPF varies from person to person. In some cases, fibrosis develops quickly, while in others, the process is much slower and the disease remains stable for years. It carries a 5-year survival rate of approximately $20 \%$, which is worse than that of several types of cancer [1,2]. Although IPF is the first or second most commonly encountered form of interstitial lung disease (ILD) (range 17-86\%), its overall incidence and prevalence are unclear. Published incidence rates have ranged from 0.6 to 17.4 per 100,000 person years. To date, there is no cure for IPF. In addition to other care options endorsed by the ATS guidelines, including pulmonary rehabilitation, long-term oxygen therapy, lung transplantation and antacid therapy, new antifibrotic drugs have recently become available [3]. Pirfenidone and nintedanib, two compounds with antifibrotic properties and pleiotropic mechanisms of action, have consistently proven to be effective in reducing functional decline and disease progression in IPF, 
and have been approved as standard of care worldwide [3, 4]. Despite substantial differences in the mechanism of action of these two compounds, their treatment effect is strikingly similar, reducing the decline of forced vital capacity (FVC) by approximately $100 \mathrm{~mL} /$ year. Individual treatment options should therefore be discussed with each newly diagnosed IPF patient, considering not only the potential benefits but also the side effects, which are not completely identical for these two drugs.

A chronic condition such as IPF may have a substantial impact on patients' quality of life (QoL) [5], and the same is true for the possible side effects of drugs used to treat this progressive disorder. Common side effects of both drugs include nausea, diarrhoea, weight loss and loss of appetite. Pirfenidone is also known to cause changes in taste and smell perception [6], while similar effects have not been reported for nintedanib. These side effects are regularly reported by patients, but relatively little is known about their real prevalence. We therefore studied the self-reported side effects of antifibrotic drugs in a Dutch sample of IPF patients.

\section{Materials and Methods}

\section{Study Design}

In cooperation with the Dutch Pulmonary Fibrosis Patient Society (Longfibrosepatiëntenvereniging Nederland), the ild care foundation has designed a questionnaire about side effects of antifibrotic drugs. This questionnaire includes questions about their disease and any problems these patients may have experienced regarding the use of antifibrotic drugs as well as other medication. In addition, it concerns the burden of disease and the symptoms experienced by patients with IPF. Respondents were asked to complete the questionnaire even if they had never experienced any problems with drug use. The questionnaire was used in a cross-sectional web-based anonymous survey, conducted from June 2018 to October 2018 among a sample of IPF patients in the Netherlands.

This study was performed in accordance with the Declaration of Helsinki and its amendments.

\section{Study Subjects and Procedure}

The overall study sample included IPF patients who were known at the outpatient clinic of the ILD Center of Excellence of the St. Antonius Hospital, Nieuwegein, the Netherlands and/or who were members of the Dutch Pulmonary Fibrosis Patient Society. All subjects had been diagnosed with IPF by a multidisciplinary team according to international guidelines [7]. Patients were recruited without incentives, since the survey was anonymous. All patients had sufficient command of the Dutch language and internet access. The survey was developed using the online questionnaire tool Surveymonkey (www.surveymonkey.com). The questions concerned the burden of disease and symptoms experienced by the patients with IPF. Further questions concerned demographics (gender, age, duration of IPF) and the use of medication. Those patients who did not use antifibrotic drugs were considered as controls.

\section{Statistical Analysis}

All statistical analyses were performed using $\mathrm{R}$ version 3.5.2, retrieved from the R Foundation for Statistical Computing [8]. To test the adverse effects of pirfenidone and nintedanib, the variables nausea, vomiting, diarrhoea, weight loss, appetite loss and loss of taste or smell perception were evaluated using logistic regression analysis with a logit link. Drug use was included as an explanatory variable, with three factors: pirfenidone $(n=71)$, nintedanib $(n=85)$ and non-drug users $(n=20)$. A correlation matrix (Table 4 in Appendix) was used to select which of the covariates of age, gender, smoking, time since diagnosis, BMI, antacid use, vitamin D, vitamin $\mathrm{K}$ and multivitamin supplementation should be included. If a covariate correlated with any of the adverse side effects from a significance level of $p \leq 0.05$, it was included in the final model.

\section{Results}

Table 1 shows demographic and clinical data from 176 Dutch patients suffering from IPF, 20 of whom did not use any antifibrotic drugs (Group 1). Pirfenidone was used by 71 patients (Group 2) and 85 patients used nintedanib (Group 3). The non-drug users (Group 1) included significantly fewer men $(p<0.01)$ than the drug users (Groups 2 and 3). Other factors did not differ significantly between these groups (Table 1). The antifibrotic drug users were not suffering from any substantial gastrointestinal comorbidities before the start of their antifibrotic treatment. Of those who did not use any antifibrotics, $10 \%$ suffered from gastrointestinal comorbidity. In five cases, gastrointestinal side effects could be assumed to be related to concomitant drugs used besides the antifibrotic drugs $(3 \times$ metformin and $2 \times$ an antidepressant). However, we did ask the participants explicitly whether their complaints had started after the initiation of the antifibrotic drugs. All but one thought there was a clear relation between starting the antifibrotic drug and the development of the complaints, and that these complaints were not attributable to other drugs they might have used. Though, it should be acknowledged that the effect of concomitant drug use can never be excluded completely. 
Table 1 Summary of the demographic and clinical data of the three idiopathic pulmonary fibrosis (IPF) patient groups

\begin{tabular}{|c|c|c|c|}
\hline & $\begin{array}{l}\text { Group } 1 \\
\text { non-drug } \\
\text { users }\end{array}$ & $\begin{array}{l}\text { Group } 2 \\
\text { Pirfenidone } \\
\text { users }\end{array}$ & $\begin{array}{l}\text { Group } 3 \\
\text { Nintedanib } \\
\text { users }\end{array}$ \\
\hline Number & 20 & 71 & 85 \\
\hline $\begin{array}{l}\text { Age (range, min-max), } \\
\text { years }\end{array}$ & $63(35-79)$ & $70(43-83)$ & $68(46-80)$ \\
\hline Gender, male $\%$ & $55^{*}$ & 81.7 & 78.8 \\
\hline Smoker, yes/no/former $\%$ & $0 / 45.0 / 55.0$ & $1.4 / 52.1 / 46.5$ & $3.5 / 35.3 / 61.2$ \\
\hline $\begin{array}{l}\text { Time since diagnosis, } \\
\text { years }\end{array}$ & $2.7 \pm 0.7$ & $2.7 \pm 0.7$ & $2.1 \pm 0.7$ \\
\hline $\begin{array}{l}\text { Having used medication } \\
\text { longer than } 12 \text { months \% }\end{array}$ & NA & 68.1 & 56.6 \\
\hline Oxygen use, $\%$ & 31.6 & 45.5 & 45.1 \\
\hline BMI $\left(\mathrm{kg} / \mathrm{m}^{2}\right)$ & $27.2 \pm 3.6$ & $26.4 \pm 3.6$ & $26.6 \pm 3.8$ \\
\hline Vitamin D, yes \% & 50 & 32.4 & 37.6 \\
\hline Vitamin K, yes \% & 25 & 15.5 & 18.8 \\
\hline Multivitamin, yes $\%$ & 15 & 11.1 & 11.8 \\
\hline Antacid, yes\% & 78.9 & 73.2 & 71.8 \\
\hline
\end{tabular}

Data are expressed as mean \pm SD or percentage if appropriate

$B M I$ body mass index, $N A$ not applicable

${ }^{*} p$ value $<0.01$ group 1 vs $2+3$
Figure 1 shows the side effects among the three IPF patients groups.

Nintedanib users reported significantly more diarrhoea and weight loss than Group 1 (controls: non-drug users). Because none of the respondents in Group 1 reported vomiting, it was not possible to statistically test for a direct effect. However, there was a significant difference between pirfenidone and nintedanib users in the incidence of vomiting, which was higher among nintedanib users.

Pirfenidone users were more likely to suffer weight loss than subjects in Group 1.

Table 2 shows the effect of both drugs on the occurrence of side effects, taking correlated covariates into account (Table 4 in Appendix).

Nintedanib $(p=0.02)$ was associated with nausea, while pirfenidone $(p=0.11)$ did not have an significant influence. The significant influence $(p<0.01)$ of the covariate of gender showed that men were significantly less likely to suffer from nausea than women.

As regards diarrhoea, nintedanib was associated with significantly increased $(p<0.01)$ diarrhoea complaints, while pirfenidone $(p=0.41)$ did not show any effect. Both nintedanib $(p<0.01)$ and pirfenidone $(p<0.01)$ users reported significantly reduced appetite, with women
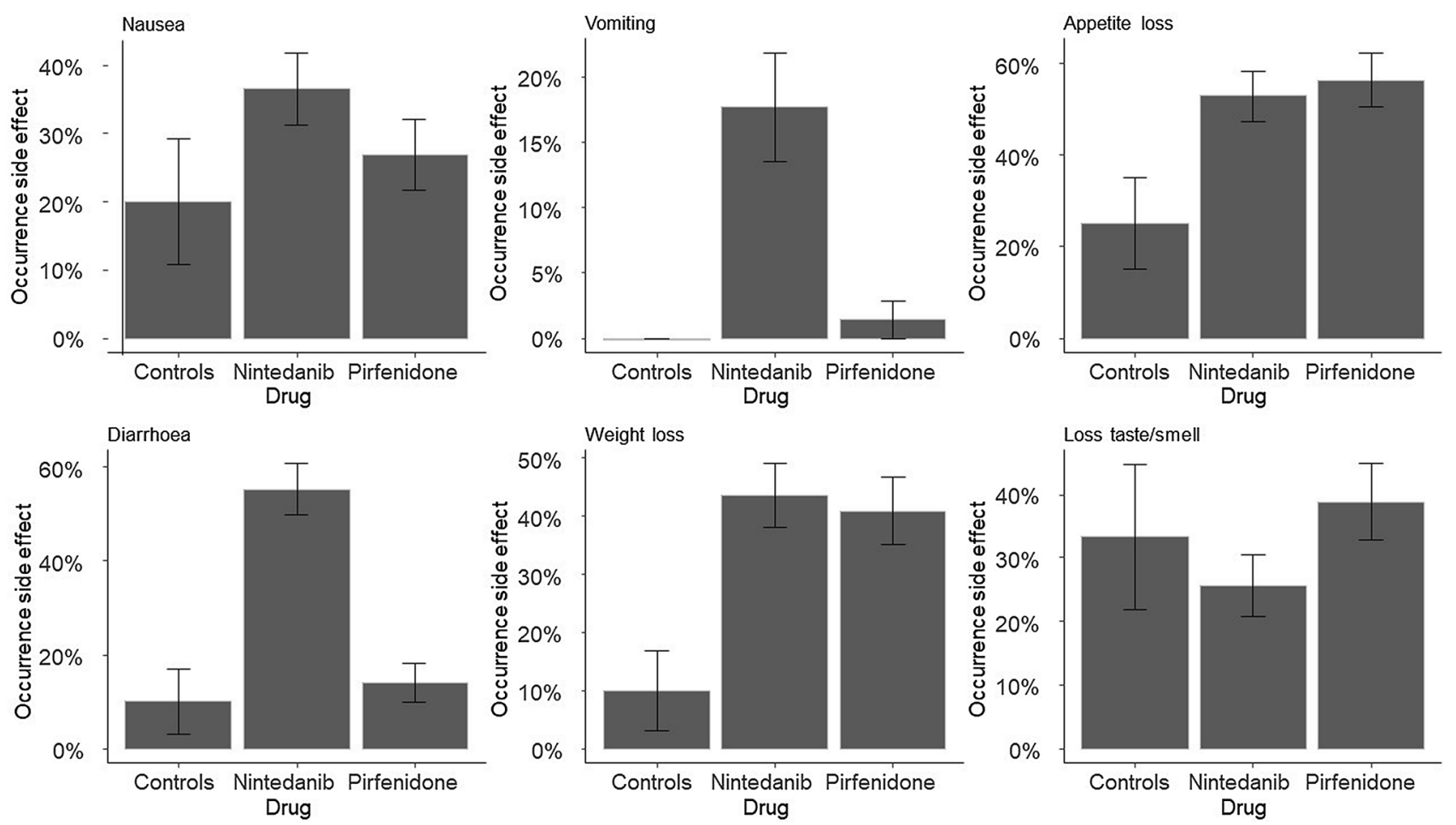

Fig. 1 Complaints among IPF patients using nintedanib, pirfenidone or neither (controls). *Value differs significantly from controls $(p<0.05)$. ${ }^{\#}$ Value differs significantly from other drug group $(p<0.05)$ 
Table 2 Occurrence of side effects among drug users

\begin{tabular}{|c|c|c|c|c|}
\hline & Coefficient & Std. Error & $Z$ value & $P$ value \\
\hline \multicolumn{5}{|l|}{ Nausea } \\
\hline Intercept & -0.62 & 0.61 & -1.03 & 0.30 \\
\hline Nintedanib & 1.51 & 0.68 & 2.24 & $0.02 *$ \\
\hline Pirfenidone & 1.03 & 0.69 & 1.50 & 0.13 \\
\hline Gender & -1.84 & 0.42 & -4.39 & $<0.01 *$ \\
\hline \multicolumn{5}{|l|}{ Diarrhoea } \\
\hline Intercept & -2.20 & 0.75 & -2.95 & $<0.01^{*}$ \\
\hline Nintedanib & 2.41 & 0.78 & 3.10 & $<0.01 *$ \\
\hline Pirfenidone & 0.39 & 0.82 & 0.48 & 0.64 \\
\hline \multicolumn{5}{|l|}{ Appetite loss ${ }^{a}$} \\
\hline Intercept & -1.48 & 0.71 & -2.10 & $0.036^{*}$ \\
\hline Nintedanib & 2.34 & 0.72 & 3.24 & $<0.01^{*}$ \\
\hline Pirfenidone & 2.50 & 0.73 & 3.42 & $<0.01 *$ \\
\hline Gender & -1.69 & 0.49 & -3.46 & $<0.01 *$ \\
\hline Antacid & 0.92 & 0.38 & 2.42 & $0.016^{*}$ \\
\hline \multicolumn{5}{|l|}{ Weight loss ${ }^{\mathrm{a}}$} \\
\hline Intercept & -0.89 & 1.62 & -0.55 & 0.58 \\
\hline Nintedanib & 2.08 & 0.8 & 2.59 & $<0.01^{*}$ \\
\hline Pirfenidone & 1.98 & 0.81 & 2.43 & $0.015^{*}$ \\
\hline BMI & -0.11 & 0.05 & -2.09 & $0.036^{*}$ \\
\hline Vit.D & 0.8 & 0.36 & 2.24 & $0.025^{*}$ \\
\hline Antacid & 1.37 & 0.44 & 3.08 & $<0.01^{*}$ \\
\hline $\begin{array}{l}\text { Loss of taste or } \\
\text { smell }\end{array}$ & \multicolumn{4}{|c|}{ Perception $^{\mathrm{b}}$} \\
\hline Intercept & -2.25 & 0.95 & -2.37 & $0.018^{*}$ \\
\hline Nintedanib & 0.32 & 0.66 & 0.48 & 0.63 \\
\hline Pirfenidone & 1.00 & 0.67 & 1.50 & 0.13 \\
\hline Gender & -1.26 & 0.44 & -2.87 & $<0.01^{*}$ \\
\hline $\begin{array}{l}\text { Time since diag- } \\
\text { nosis }\end{array}$ & 0.46 & 0.26 & 1.75 & 0.080 \\
\hline Antacid & 1.06 & 0.46 & 2.3 & $0.021 *$ \\
\hline
\end{tabular}

${ }^{\mathrm{a}} 1$ observation deleted due to missing value

${ }^{\mathrm{b}} 10$ observations deleted due to missing values

*Significant influence

$(p<0.01)$ reporting significantly more appetite loss than men. Antacid use $(p<0.05)$ also increased appetite loss.

Weight loss appeared to be significantly higher among nintedanib users $(p<0.01)$ compared with non-drug users, while pirfenidone $(p=0.015)$ seemed to be associated with to have a less weight loss. A higher BMI was associated with a lower risk of weight loss $(p<0.05)$, whereas vitamin D use increased weight loss. Antacid use $(p<0.01)$ was also associated with significantly increased weight loss.

Finally, even though $31 \%$ of the respondents reported to suffer from a decrease in appetite or smell perception, Table 1 shows that this cannot be attributed to their drug use. Other covariates that tended to have an effect included gender $(p=0.01)$, as women were significantly more likely to suffer from loss of appetite or smell, and antacid use $(p=0.021)$, which increased the risk of loss of taste or smell perception.

\section{Discussion}

Ideally, a progressive and almost invariably fatal disease like IPF should be treated, unless there is clear evidence of a lack of response. Benefits and burden of treatment should be discussed with every newly diagnosed IPF patient, taking his/her unique profile into account (Table 3). It is therefore important to gain more insights into the way the drugs work and their possible side effects. The current study found a difference in self-reported side effects between the two antifibrotic drugs nintedanib and pirfenidone among an IPF sample. In the majority of the cases, the use of the drug was continued despite the side effects. Among the 24 respondents who switched from pirfenidone to nintedanib, 21 mentioned side effects as an underlying reason. Among the five respondents switching from nintedanib to pirfenidone, two respondents mentioned side effects as an underlying reason.

Nintedanib users $(48.3 \%)$ reported suffering from a significant increase in diarrhoea, weight loss, vomiting and loss of appetite, compared with non-drug users (11.4\%). Pirfenidone users (40.3\%) reported a significant increase in loss of appetite and weight loss. The degree of weight loss and loss of appetite did not differ significantly between the two groups of drug users. Other side effects reported by respondents in our study included dry mouth, dyspepsia, sun allergy and skin rash (data not shown), which was in line with a previous study by Bennet et al. [9].

Previous studies on the side effects of antifibrotic drugs have reported similar results. The nausea and vomiting associated with nintedanib (Fig. 1) was also found in previous research [10,11]. By contrast, the association between pirfenidone and nausea or vomiting as found by previous studies was not confirmed by our results $[12,13]$. A possible explanation could be that $68.1 \%$ of our respondents had used pirfenidone for more than 12 months, while most stomach complaints manifest within the first 3 months and decrease over time [14]. Furthermore, the problem of nausea can be reduced by taking pirfenidone immediately after food consumption [15].

The weight loss, loss of appetite and diarrhoea reported for nintedanib users in previous studies were in line with our current data, which also showed a significant prevalence $[10$, $11,16,17]$. In order to counter these side effects, it could useful to look into dietary interventions. For example, the official nintedanib website recommends the Bananas Rice Applesauce Toast (B.R.A.T.) diet to counter diarrhoea [18].

Our pirfenidone users reported an increase in loss of appetite and weight loss, which is also in agreement with results 
Table 3 Patients' comments in the survey: advice for prescribers

Prescribers should give patients guidance about taking medication to reduce side effects, such as what time of the day to take medication, or if it should be taken with food, and possible interactions. Hospital and/or community pharmacists could play a role, especially with regard to patients' other possible drug use, e.g. statins

Prescribers should reassure patients about the variation in medication they are using, and inform them about possible interactions with other drugs, explaining why the combination is necessary

Prescribers should review any treatments prior to receiving the IPF diagnosis, such as long-term steroid use, and check for a risk of antibiotic resistance

from previous studies $[13,19,20]$. Finally, $31 \%$ of all respondents reported suffering from loss of taste or smell perception. Our data showed, however, that this was not caused by antifibrotic drug use. The loss of taste or smell perception could be influenced by covariates related to IPF. Women appeared more prone to loss of taste or smell perception than men, and antacid use also affected taste and smell perception. Another possible cause could be that the disease itself influences taste and smell perception. Reduced taste perception is also found in other lung diseases like COPD and lung cancer [21-24]. Lung function could play an important role in taste or smell perception. A possible underlying cause could be a relation between lung retention and retronasal smell perception, as suggested in a previous study [25]. Taste and smell perceptions are related and therefore retronasal smell perception could also influence taste. This process has also been suggested to play an important role in the flavour perception of vaping [25]. Another study found that lung retention, measured by the release of $\mathrm{N}$-isopropyl$\mathrm{p}\left[{ }^{123} \mathrm{I}\right]$-iodoamphetamine ( ${ }^{123} \mathrm{I}$-IMP) by the lung after ${ }^{123} \mathrm{I}$-IMP injection, was prolonged in lung fibrosis patients [26].

Besides knowing which side effects can occur due to the current treatment, it is also important to analyse whether this leads to drug discontinuation. In our study, drug discontinuation was rather rare. Two pirfenidone and one nintedanib user stopped their antifibrotic medication completely due to the side effects (data not shown).

In the ASCEND and CAPACITY studies, the reported pirfenidone side effects of skin rash, nausea and dyspepsia did not lead to drug discontinuation in the clinical trials $[12,13,27]$. Similarly, although more than $60 \%$ of patients receiving nintedanib experienced diarrhoea in the INPULSIS trials, this was often adequately controlled by dose reduction or anti-diarrhoeal medication, with $<5 \%$ of them having to discontinue the medication completely [28].

\section{Limitations}

One of the limitations of this study is that information about disease severity was lacking, so the impact of disease severity on the side effects could not be established. Another limitation is that the symptoms were self-reported and not objectified by a health care professional.

\section{Recommendations}

The data retrieved from our study show that both nintedanib and pirfenidone carry a high burden of gastrointestinal side effects. However, in line with real-life experiences which have clearly demonstrated that the gastrointestinal side effects rarely result in treatment discontinuation [29], only a few patients $(n=3)$ in the present study ultimately had to discontinue their medication. Therefore, it would be useful to look into possible dietary interventions to minimise this burden, as well as the use of other drugs to counter these side effects. It should be acknowledged that patients welcome supportive care throughout the trajectory of the disease, and patients should be supported at each step of the process. In this regard, accessible support from care providers, especially from ILD specialist nurses and nurse practitioners, plays a crucial role in shared decision making and handling gastrointestinal side effects of antifibrotics [30-32]. Strategies to manage gastrointestinal side effects caused by one of the antifibrotics start with the advice to take the tablets of both agents during a meal, not on an empty stomach, and to divide the dosage across the meal [33]. Thus, a reduction of the peak dose can be achieved by taking the medication with food [34]. In case of persistent diarrhoea, the next step may be rehydration and anti-diarrhoeal medication, for example, loperamide [35], and in case of persistent nausea, anti-emetics [36]. Furthermore, antacids are recommended in case of indigestion [33]. In addition to pirfenidone and nintedanib, there is also a conditional recommendation for proton-pump inhibitors in IPF treatment [37]. Because there is a risk of pharmacokinetic interaction between pirfenidone and omeprazole, this should be avoided when using pirfenidone, but may be given with nintedanib [30]. In contrast to what is known about pirfenidone and nintedanib, the data supporting the effect of antacid therapy in IPF are of poor quality (e.g. observational/retrospective studies and post hoc analysis of patients assigned to placebo arms in clinical trials of pharmaceutical interventions). The guidelines do acknowledge the need for further research on the efficacy and longterm safety of antacid therapy as well as interactions with other IPF medications. 


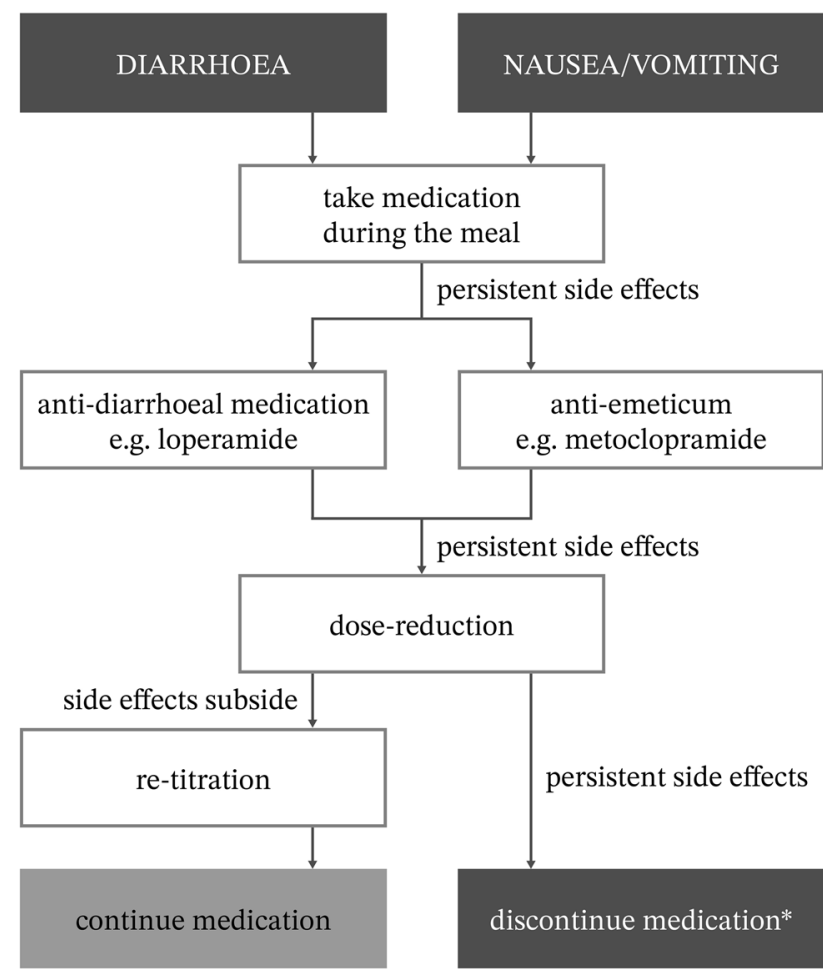

Fig. 2 Algorithm for the management of gastrointestinal side effects of pirfenidone or nintedanib. *If a patient finds the side effects intolerable, and he/she really wants to stop. Optional: referral to a dietician and/or starting proton-pump inhibition

Although it is not 'a one size fits all' policy in case of persistent side effects, supervised dose reduction and retitration may be required once the symptoms have subsided [30]. In case of weight loss, the decision depends on the patients' own opinion. If the weight loss is more than $10 \%$, patients should be referred to a dietician. An algorithm for the practical management of gastrointestinal side effects of pirfenidone or nintedanib, based on patients' decisions and clinical practice, is presented in Fig. 2.

All authorised products of nintedanib and pirfenidone in the European Union are listed for close monitoring. These products are marked by regulatory authorities as requiring additional monitoring with regard to adverse drug reactions [38].

\section{Conclusion}

Information about possible side effects is important if patients are to receive the best antifibrotic treatment available. The current study showed that the two antifibrotic drugs nintedanib and pirfenidone have different side effects.

Nintedanib users reported a significant increase in diarrhoea, vomiting, weight loss, and loss of appetite, while pirfenidone users suffered primarily from an increase in loss of appetite. In addition, nintedanib was associated with nausea and pirfenidone with weight loss.

Our data showed that 24 respondents had switched from pirfenidone to nintedanib in the past, while five had switched from nintedanib to pirfenidone, suggesting that although nintedanib gave rise to more gastrointestinal side effects, the general burden of side effects of nintedanib is probably lower.

Both pirfenidone and nintedanib carry a rather high burden of gastrointestinal side effects, so it could be useful to look into dietary interventions to minimise this burden.

Acknowledgements The authors would like to thank the Dutch Fibrosis Patient Society (www.longfibrose.nl) and all participants in this study for all their efforts to make this project a success. We also wish to thank Annemieke van Dort, nurse practitioner ILD Center of Excellence, Nieuwegein, the Netherlands for helping preparing the algorithm for the management of gastrointestinal side effects.

Author Contributions All authors were involved in the study design and data collection. VP, MD, and $\mathrm{AB}$ analysed the data and drafted the manuscript. ME conducted the survey. ME, NJ, and PW revised the manuscript critically for important intellectual content. All authors read and approved the final manuscript.

Funding This study was supported by a research grant of the ild care foundation: www.ildcare.nl. The study sponsor had no involvement in the study design; in the collection, analysis, and interpretation of data; in the writing of the manuscript; or in the decision to submit the manuscript for publication.

Data Availability The datasets used and/or analysed during the current study are available from the corresponding author on reasonable request.

\section{Compliance with Ethical Standards}

Conflict of interest The authors declare that they have no competing interests.

Ethical Approval In accordance with the Dutch Act on Human Subjects Medical Research, the Medical Ethics Committee of St. Antonius Hospital Nieuwegein waived formal approval.

Open Access This article is distributed under the terms of the Creative Commons Attribution 4.0 International License (http://creativeco mmons.org/licenses/by/4.0/), which permits unrestricted use, distribution, and reproduction in any medium, provided you give appropriate credit to the original author(s) and the source, provide a link to the Creative Commons license, and indicate if changes were made.

\section{Appendix}

See Table 4. 
Table 4 Correlation matrix used to define covariates

\begin{tabular}{llllccc}
\hline & Nausea & Vomiting & Diarrhoea & Weight loss & Appetite loss & Loss taste/smell \\
\hline Age & -0.04 & -0.03 & -0.14 & 0.02 & 0.04 & 0.01 \\
Gender & $-0.33^{* *}$ & $-0.26^{* *}$ & 0.12 & -0.03 & $-0.22^{* *}$ & $-0.25^{* *}$ \\
BMI & 0.00 & -0.05 & 0.01 & $-0.20^{* *}$ & -0.11 & -0.07 \\
Time since & -0.06 & -0.01 & 0.07 & 0.06 & 0.05 & $0.19^{*}$ \\
$\quad$ diagnosis & & & & & & \\
Smoking & 0.02 & $0.20^{* *}$ & 0.09 & 0.09 & 0.06 & -0.11 \\
Vit.D & 0.13 & 0.09 & -0.14 & $0.19^{*}$ & 0.11 & 0.07 \\
Vit.K & 0.07 & 0.06 & -0.12 & 0.08 & 0.08 & 0.06 \\
Antacid & 0.10 & 0.01 & -0.14 & $0.27^{* *}$ & $0.18^{*}$ & $0.19^{*}$ \\
Multivit & 0.02 & -0.06 & -0.11 & -0.11 & -0.06 & -0.01 \\
Oxygen use & 0.04 & 0.08 & 0.08 & -0.07 & -0.07 & -0.03 \\
\hline
\end{tabular}

If a $p$ value was lower than 0.05 , the covariate was included

${ }^{*} p<0.05 ; * * p<0.01$

\section{References}

1. Ley B, Collard HR (2013) Epidemiology of idiopathic pulmonary fibrosis. Clin Epidemiol 5:483-492

2. Barratt SL, Creamer A, Hayton C, Chaudhuri N (2018) Idiopathic pulmonary fibrosis (IPF). An overview. J Clin Med 7(8):201

3. Raghu G, Rochwerg B, Zhang Y et al (2015) An official ATS/ ERS/JRS/ALAT clinical practice guideline: treatment of idiopathic pulmonary fibrosis. An update of the 2011 clinical practice guideline. Am J Respir Crit Care Med 192(2):e3-e19

4. Zurkova M, Kriegova E, Kolek V et al (2019) Effect of pirfenidone on lung function decline and survival: 5-year experience from a real-life IPF cohort from the Czech EMPIRE registry. Respir Res 20(1):16

5. Yount SE, Beaumont JL, Chen S-Y, Kaiser K, Wortman K, Van Brunt DL, Swigris J, Cella D (2016) Health-related quality of life in patients with idiopathic pulmonary fibrosis. Lung 194(2):227-234

6. Agency EM (2015) INN-pirfenidone. https://www.ema.europ a.eu/en/documents/product-information/esbriet-epar-productinformation_nl.pdf

7. Raghu G, Remy-Jardin M, Myers JL et al (2018) Diagnosis of idiopathic pulmonary fibrosis. An official ATS/ERS/JRS/ALAT clinical practice guideline. Am J Respir Crit Care Med 198(5):e44-e68

8. Team RC (2013) R: a language and environment for statistical computing. https://www.R-project.org/

9. Bennett D, Refini RM, Valentini ML, Fui A, Fossi A, Pieroni M, Mazzei MA, Rottoli P (2019) Pirfenidone therapy for familial pulmonary fibrosis: a real-life study. Lung 197(2):147-153

10. Crestani B, Huggins JT, Kaye M et al (2019) Long-term safety and tolerability of nintedanib in patients with idiopathic pulmonary fibrosis: results from the open-label extension study, INPULSIS-ON. Lancet Respir Med 7(1):60-68

11. Fala L (2015) Ofev (Nintedanib): first tyrosine kinase inhibitor approved for the treatment of patients with idiopathic pulmonary fibrosis. Am Health Drug Benefits 8(Spec Feature):101

12. King TE Jr, Bradford WZ, Castro-Bernardini S et al (2014) A phase 3 trial of pirfenidone in patients with idiopathic pulmonary fibrosis. New Eng J Med 370(22):2083-2092

13. Noble PW, Albera C, Bradford WZ et al (2011) Pirfenidone in patients with idiopathic pulmonary fibrosis (CAPACITY): two randomised trials. Lancet 377(9779):1760-1769
14. Esbriet(pirfenidone)tablets (2019) Managing certain esbriet side effects. https://www.esbriet.com/taking-esbriet/managing-certa in-side-effects.html

15. Esbriet(pirfenidone)tablets (2019) How to take esbriet. https:// www.esbriet.com/taking-esbriet/how-to-take-esbriet.html

16. Bonella F, Kreuter M, Hagmeyer L et al (2016) Insights from the German compassionate use program of nintedanib for the treatment of idiopathic pulmonary fibrosis. Respir 92(2):98-106

17. Corte T, Bonella F, Crestani B et al (2015) Safety, tolerability and appropriate use of nintedanib in idiopathic pulmonary fibrosis. Respir Res 16(1):116

18. Nintedanib O (2019) About diarrhea, nausea and vomiting. https ://www.ofev.com/about-ofev/side-effects/about-diarrhea-nause a-vomiting

19. Ogura T, Azuma A, Inoue $Y$ et al (2015) All-case post-marketing surveillance of 1371 patients treated with pirfenidone for idiopathic pulmonary fibrosis. Respir Investig 53(5):232-241

20. Wijsenbeek MS, Grutters JC, Wuyts WA (2015) Early experience of pirfenidone in daily clinical practice in Belgium and the Netherlands: a retrospective cohort analysis. Adv Ther 32(7):691-704

21. Wardwell L, Chapman-Novakofski K, Brewer MS (2009) Effects of age, gender and chronic obstructive pulmonary disease on taste acuity. Int J Food Sci Nutr 60(sup6):84-97

22. Ito K, Kohzuki M, Takahashi T, Ebihara S (2014) Improvement in taste sensitivity following pulmonary rehabilitation in patients with chronic obstructive pulmonary disease. J Rehab Med 46(9):932-936

23. Dewan NA, Bell CW, Moore J, Anderson B, Kirchain W, O'Donohue WJ Jr (1990) Smell and taste function in subjects with chronic obstructive pulmonary disease: effect of long-term oxygen via nasal cannulas. Chest 97(3):595-599

24. Williams L, Cohen M (1978) Altered taste thresholds in lung cancer. Am J Clin Nutri 31(1):122-125

25. Verhagen JV (2015) A role for lung retention in the sense of retronasal smell. Chemosens Percept 8(2):78-84

26. Ikeda H, Itasaka M, Takahashi K, Komatani A (1992) Prolonged lung retention of 123 I-IMP in pulmonary fibrosis. Ann Nucl Med 6(3): 147

27. Valeyre D, Albera C, Bradford WZ et al (2014) Comprehensive assessment of the long-term safety of pirfenidone in patients with idiopathic pulmonary fibrosis. Respirology 19(5):740-747

28. Costabel U, Richeldi L, du Bois RM et al (2015) Efficacy and safety of nintedanib in patients with idiopathic pulmonary fibrosis: 
results of two 52-week, Phase III, randomized, placebo-controlled trials (INPULSIS ${ }^{\mathrm{TM}}$ ). Pneumologie 69(S 01):P235

29. Hughes G, Toellner H, Morris H, Leonard C, Chaudhuri N (2016) Real world experiences: pirfenidone and nintedanib are effective and well tolerated treatments for idiopathic pulmonary fibrosis. J Clin Med 5(9):78

30. Shaw J, Marshall T, Morris H, Hayton C, Chaudhuri N (2017) Idiopathic pulmonary fibrosis: a holistic approach to disease management in the antifibrotic age. J Thorac Dis 9(11):4700-4707

31. Russell AM, Ripamonti E, Vancheri C (2016) Qualitative European survey of patients with idiopathic pulmonary fibrosis: patients' perspectives of the disease and treatment. BMC Pulm Med 16:10

32. Duck A, Spencer LG, Bailey S, Leonard C, Ormes J, Caress AL (2015) Perceptions, experiences and needs of patients with idiopathic pulmonary fibrosis. J Adv Nurs 71(5):1055-1065

33. Costabel U, Bendstrup E, Cottin V et al (2014) Pirfenidone in idiopathic pulmonary fibrosis: expert panel discussion on the management of drug-related adverse events. Adv Ther 31(4):375-391

34. Rubino CM, Bhavnani SM, Ambrose PG, Forrest A, Loutit JS (2009) Effect of food and antacids on the pharmacokinetics of pirfenidone in older healthy adults. Pulm Pharmacol Ther 22(4):279-285

35. Mazzei ME, Richeldi L, Collard HR (2015) Nintedanib in the treatment of idiopathic pulmonary fibrosis. Ther Adv Respir Dis 9(3):121-129

36. Edwards IR, Aronson JK (2000) Adverse drug reactions: definitions, diagnosis, and management. Lancet 356(9237):1255-1259

37. Raghu G, Collard HR, Egan JJ et al (2011) An official ATS/ERS/ JRS/ALAT statement: idiopathic pulmonary fibrosis: evidencebased guidelines for diagnosis and management. Am J Respir Crit Care Med 183(6):788-824

38. Agency EM (2018) List of medicines under additional monitoring. https://www.ema.europa.eu/en/human-regulatory/post-autho risation/pharmacovigilance/medicines-under-additional-monit oring/list-medicines-under-additional-monitoring

Publisher's Note Springer Nature remains neutral with regard to jurisdictional claims in published maps and institutional affiliations. 